\title{
Progressive Care Certified Nurse
}

National Cancer Institute

\section{Source}

National Cancer Institute. Progressive Care Certified Nurse. NCI Thesaurus. Code

C71338.

A critical care nurse with specialized training in prog ressive care, which describes areas

referred to as intermediate care units, direct observation units, step-down units,

telemetry and transitional care units as well as a specific level of care. 